economia volta a aquecer-se, as indústrias tratam, inicialmente, de ocupar sua capacidade produtiva e, só posteriormente, efetuam um novo ciclo de investimentos para a ampliação da produção, o que, só então, leva à aquisição de novos equipamentos da indústria de bens de capital - BNDES (BANCO..., 2006).

Este artigo estende os estudos sobre a IBCE, em especial dos fabricantes de bens de capital de grande porte, também conhecidos como sistemas de produção de grandes montagens, com o objetivo de propor um método de implantação conjunta dos princípios da produção enxuta e da teoria das restrições (TOC) nesse ambiente, com a utilização dos Sistemas de Coordenação de Ordens (SCOs) adequados, de modo a reduzir o lead time de produção e melhorar a pontualidade de entrega. Embora já existam estudos publicados sobre a implantação, em segmentos específicos da IBCE, tanto da produção enxuta (na indústria naval (STORCH; LIM, 1999; LIKER; LAMB, 2001)), indústria aeronáutica (DUDLEY, 2005; CRUTE et al., 2003) e máquinas e ferramentas (JINA; BHATTACHARYA; WALTON, 1997; ESWARAMOORTHI; KATHIRESAN; MOHANRAM, 2010) como da TOC (GUPTA; KO; MIN, 2002; CHAKRAVORTY, 2001; LEE et al., 2010), não existe na literatura da área de gestão da produção um método genérico para a implementação conjunta dos seus princípios nesse ambiente, e a proposta de tal método é o objetivo principal deste artigo.

Dos diversos aspectos estudados sobre a IBCE, é evidenciado que a customização nesse ambiente é vista como fundamental para manter e aumentar a participação de mercado. Embora tais empresas possam fornecer grande número de produtos padronizados, algum grau de customização é sempre exigido pelos clientes desse setor (SIEVÄNEN, 2004).

Sobre a IBCE, vale lembrar que: i) o processo de fabricação é intensivo de mão de obra e pouco automatizado, porém as máquinas, quando existem, são, geralmente, de grande porte, de uso universal; ii) o layout é tradicionalmente funcional (jobshop); iii) a mão de obra é mais estável devido aos longos tempos de treinamento (MEGLIORINI, 2003); iv) é comum nessas empresas utilizar a unidade HH (horas-homem) ou HM (horas-máquina) disponíveis como unidade de capacidade, e a capacidade total é, então, dada pelo produto do número de recursos similares pelo número de horas de trabalho efetivo requerido; v) a estratégia de resposta à demanda típica é a ETO (Engineering to Order). Little et al. (2000) afirmam que empresas ETO que fabricam produtos de alto valor agregado têm tentado aumentar sua responsividade aos clientes, em velocidade e pontualidade de entrega, sem comprometer o desempenho de seus produtos.
As questões de pesquisa são: i) Os princípios e técnicas da produção enxuta e da TOC podem ser aplicados de forma conjunta ao ambiente da IBCE? ii) Os SCOs Constant Work in Process (CONWIP) e Brum-Buffer-Rope (DBR) podem ser utilizados para sustentar os princípios da produção enxuta e da TOC nesse ambiente? Para responder a estas questões, além da revisão bibliográfica pertinente, o método proposto será implantado, por meio de pesquisa-ação, em uma empresa fabricante de máquinas e equipamentos sob encomenda para a indústria de papel e celulose.

$\mathrm{O}$ método de pesquisa utilizado neste artigo foi a pesquisa-ação. Segundo Coughlan e Coghlan (2002), a pesquisa-ação focaliza a pesquisa na ação, ao invés de uma pesquisa sobre a ação. O propósito é tornar essa ação mais eficaz enquanto, simultaneamente, se constrói o conhecimento científico. Segundo Thiollent (2000), pesquisa-ação é um tipo de pesquisa social com base empírica, concebida e realizada em estreita associação com determinada ação ou com a resolução de um problema coletivo. $\mathrm{Na}$ pesquisa-ação, pesquisadores de um lado e participantes representativos da situação do outro estão envolvidos de modo cooperativo ou participativo. Esta pesquisa caminhou exatamente nesse sentido. Teve início no ano de 2004, quando a empresa decidiu estudar a possibilidade de aplicação dos princípios da produção enxuta no seu sistema de produção. Com a definição do time de implantação e a falta de um método de aplicação da produção enxuta na IBCE na literatura, o pesquisador (o primeiro autor deste artigo, que foi, durante o período de criação e implementação do método, entre os anos de 2004 a 2011, um dos coordenadores da implementação, gerenciador de uma das linhas de produto em que o método foi implantado e gerente de planejamento e controle de produção da empresa) iniciou a pesquisa para propor um método para tal aplicação. À medida que o método foi sendo desenvolvido e a implementação foi sendo realizada em projetos pilotos, surgiram dificuldades e oportunidades de melhoria que se refletiram na proposta do método mostrada neste trabalho, principalmente no que se refere à inclusão da TOC e dos SCOs híbridos para dar suporte aos princípios da produção enxuta nesse ambiente.

Segundo Turrioni e Mello (2010), o processo cíclico de uma pesquisa-ação compreende cinco passos que foram seguidos pela pesquisa-ação deste artigo, a saber: i) planejamento da pesquisa que compreende a proposta do método (seção 4) a ser implantado, incentivo da empresa pela pesquisa e implementação, além da definição dos responsáveis pela implementação, conforme citado anteriormente; ii) coleta de dados (parte dos dados coletados está apresentada na seção 5); iii) análise de dados (apresentação na seção 5); iv) tomada de ação: a implementação se deu em diversas etapas, entre as 
quais a mudança de layout, que exigiu a mudança de posição de máquinas de grande porte, e o treinamento dos colaboradores para a multifuncionalidade foram as ações mais demoradas; v) avaliação da ação: com a implantação do método, foram obtidos diversos resultados positivos, enunciados na seção 5 .

Este artigo está organizado em mais cinco seções: a seção 2 revisa os princípios e a aplicação da produção enxuta na IBCE; na 3, é apresentada a TOC; na 4, é proposto um método de aplicação dos princípios da produção enxuta e da TOC nesse ambiente; na 5, é apresentada a pesquisa-ação, com a implementação do método proposto em um fabricante de equipamentos sob encomenda para a indústria de papel e celulose; e, na última seção, são apresentadas as conclusões deste trabalho.

\section{Produção enxuta}

Os princípios e práticas do que é atualmente conhecida como produção enxuta têm como base o Sistema Toyota de Produção (TPS), desenvolvido a partir da década de 1940 para enfrentar certas restrições de mercado que, segundo Ohno (1997), em função da baixa demanda exigiam a produção de pequenas quantidades de muitas variedades de modelo, um destino que a indústria japonesa enfrentou no período do pós-guerra. O TPS ganhou notoriedade com a divulgação dos resultados do International Motor Vehicle Program, um programa de pesquisas ligado ao MIT (Massachusetts Institute of Technology), que, nos anos 1980, estudou as melhores práticas gerenciais e de melhoria adotadas por empresas líderes do mercado automotivo mundial, e com a publicação do livro "A Máquina que Mudou o Mundo" de Womack, Jones e Ross (1992), que popularizou o termo produção enxuta, cujos princípios fundamentais são: i) especificar valor para os clientes; ii) identificar o fluxo de valor, as atividades que criam valor para o cliente; iii) realizar as atividades em fluxo contínuo onde for possível; iv) implementar a produção puxada onde o fluxo contínuo não for possível; e v) buscar a perfeição de forma incessante por meio de um processo de melhoria contínua (WOMACK; JONES, 1998; HINES; TAYLOR, 2000). Entre esses, os princípios do fluxo contínuo e da produção puxada, além do nivelamento de produção e o Takt Time, são os elementos de fluxo da produção enxuta mais importantes para este artigo.

Rother e Shook (2003) afirmam que o fluxo contínuo é o modo mais eficiente de se produzir um bem. Segundo Shingo (1996), o fluxo contínuo e unitário de peças por meio dos processos tem como resultado reduções radicais no lead time de produção e, para atingi-lo, é preciso: i) efetuar o balanceamento das quantidades de produção entre cada processo e a sincronização destes para eliminar as esperas de processo, o que exige que, mesmo que a capacidade de cada um seja diferente, devem ter a mesma velocidade; ii) reduzir o tamanho do lote de transferência para um; iii) melhorar o layout com utilização de linhas ou células de produção; e iv) reduzir o tamanho do lote de processamento, o que é possível pelo uso do sistema de troca rápida de ferramenta SMED (Single Minute Exchange of Dies). Naturalmente, o ideal de fluxo contínuo de peças não é possível em qualquer situação e o princípio da produção puxada, com a definição de buffers (pulmões ou estoques amortecedores), deve ser utilizado onde o fluxo contínuo não for possível.

O princípio da produção puxada: i) tem por finalidade evitar a superprodução, mantendo uma coordenação entre os processos que não possam ser conectados por meio do fluxo contínuo, controlando o estoque em processo do sistema (LIKER, 2005); ii) mantém uma interdependência recíproca no fluxo de valor, ou seja, um relacionamento de mão dupla entre alguns processos (SIPPER; BULFIN, 1997); iii) explicitamente limita a quantidade de estoque em processo (WIP) que pode estar no sistema (HOPP; SPEARMAN, 2004); e iv) define que o gatilho da produção, a autorização para a liberação de trabalho para o sistema de produção, está dentro do sistema de produção (HOPP; SPEARMAN, 2004). Este princípio pode ser alcançado tanto com a utilização de SCOs puxados ou controlados pelo nível de estoque (CNE), com todos os processos programados por um sinal vindo de um estágio posterior do fluxo, como o Kanban (OHNO, 1997; MONDEN, 1984), quanto com SCOs híbridos, que têm o gatilho da produção dentro do sistema de produção, mas com um dos estágios programado pelo $\mathrm{PCP}$, por exemplo, o CONWIP, que utiliza um número restrito de cartões por linha de produção, e quando um item entra na linha recebe um cartão que só é retirado ao término de seu processamento, quando o cartão é enviado ao início para ser anexado a outro item. O primeiro processo é programado por uma backlog list com a sequência de fabricação (SPEARMAN et al., 1990),

Para alcançar e sustentar os princípios do fluxo contínuo e da produção puxada, todo o fluxo de valor deve ser nivelado e controlado pelo Takt Time. Segundo Ohno (1997), o Takt Time é o tempo alocado para se produzir uma unidade e pode ser calculado dividindo-se as horas de operação diária da fábrica pela quantidade de unidades necessárias por dia. O Takt Time é o inverso da taxa de demanda. Já, o Takt Time efetivo é o ritmo de produção necessário para atender a um determinado nível considerado de demanda, dadas as restrições atuais de capacidade da linha ou célula (ALVAREZ; ANTUNES JUNIOR, 2001).

Segundo Monden (1984), o nivelamento de produção é a base do TPS e sua condição mais importante para possibilitar os princípios do fluxo 
contínuo e da produção puxada. Para Ohno (1997), as flutuações do volume de trabalho na produção fazem aumentar o desperdício. Tentar implementar o fluxo contínuo e unitário de peças, seguindo a demanda real do cliente sem nivelar a produção, irá criar um ritmo errático de produção com picos e vales (LIKER, 2005). Da mesma forma, utilizar a produção puxada antes de se realizar o nivelamento de produção irá exigir grandes níveis de inventário entre processos para acomodar os picos de demanda dos processos clientes. O nivelamento de produção deve ser feito em termos da quantidade (volume) e tipo (mix) de produtos demandados durante um período fixo de tempo.

Para atingir o nivelamento, é necessário liberar pequenos incrementos de trabalho, ou seja, reduzir e padronizar o tamanho dos lotes (volume de trabalho), para o pacemaker (processo cadenciador), o único processo que recebe a programação nivelada em um fluxo de valor, estabelecendo um ritmo de trabalho nivelado, que cria um fluxo de produção previsível no qual os problemas são evidenciados rapidamente, possibilitando rápidas ações corretivas (ROTHER; SHOOK, 2003). Esse incremento é chamado de Pitch e se torna a unidade básica de programação de produção para uma determinada família de produtos e é medido em unidades de tempo (minutos, horas, dias). Pode variar de acordo com a realidade do sistema de produção, mas deve ser tão pequeno quanto possível.

A aplicabilidade desses princípios e práticas da produção enxuta em ambientes similares ao da IBCE tem gerado grande debate no meio acadêmico. Storch e Lim (1999) apresentam a aplicação dos princípios da produção enxuta na indústria da construção naval e mostram como o fluxo contínuo e uniforme pode ser atingido em um típico sistema de produção sob encomenda. Esses autores ressaltam a utilização da tecnologia de grupo e de uma estrutura de projeto orientada a produto (PWBS) para criar um fluxo nivelado com volume de trabalho constante em todos os níveis de fabricação de um navio por meio de processos com recursos dedicados a cada família de produtos, como pré-requisitos para essa implementação. Esses mesmos autores apresentam o termo Process Lane (PL) para descrever a cadeia de recursos dedicados a cada família de produtos que compõem o navio.

Alguns autores avaliam que os métodos e ferramentas da produção enxuta não se mostram tão eficientes no ambiente sob encomenda como na indústria automotiva, em razão das características de alta variedade e baixo volume de demanda dessas empresas (BAMBER; DALE, 2000). Outros, porém, discutem que alguns princípios e ferramentas da produção enxuta são aplicados, em menor ou maior grau, em certos ambientes de produção sob encomenda: Liker e Lamb (2001), Irani (2001), Hendry (1998), Bokhorst, Slomp e Germs (2009),
Eswaramoorthi, Kathiresan e Mohanram (2010), Gambi (2011), Thompson (2009), White e Prybutok (2001), Jina, Bhattacharya e Walton (1997), Dudley (2005), Crute et al. (2003) e Stefanelli (2010). Parece consenso, portanto, que nem todas as ferramentas da produção enxuta podem ser utilizadas em ambientes similares ao da IBCE. Entretanto, esses estudos demonstram que, apesar da necessidade da escolha correta das práticas e ferramentas da produção enxuta e de certas adaptações, os princípios da produção enxuta são aplicáveis a tal ambiente.

\section{Teoria das restrições - TOC}

A TOC teve início com um pedido de ajuda ao Dr. Eliyahu Goldratt, físico israelense, para projetar um sistema de programação da produção para uma planta de galinheiros de um amigo (SIPPER; BULFIN, 1997). Ele desenvolveu um sistema informatizado que triplicou a produção da planta em um curto prazo. Esse programa foi aperfeiçoado até ser comercializado sob o nome de OPT, Optimized Production Technology (WATSON; BLACKSTONE; GARDINER, 2006).

Enquanto o sistema de software foi evoluindo, o outro lado da OPT foi desenvolvido, a estratégia de gestão OPT e suas regras, que evoluíram, posteriormente, para uma abordagem de gestão mais completa e robusta para lidar com a geração de throughput em vez da mera redução de custos. Esta abordagem ficou conhecida como TOC e apresenta cinco passos para aumentar o throughput da empresa: i) identificar a restrição do sistema; ii) explorar ao máximo a restrição do sistema; iii) subordinar todo o resto à política de exploração da restrição; iv) elevar a restrição do sistema; v) assim que a restrição for quebrada, voltar ao primeiro passo, evitando que a inércia das políticas atuais se torne uma restrição. Ou seja, a base da TOC é que toda organização tem restrições que a impedem de atingir um nível maior de desempenho e que, portanto, devem ser identificadas e geridas para aumentar o desempenho. Isso gera um processo de melhoria contínua.

As regras do OPT que formam a base para o que ficou conhecido como manufatura sincronizada (NARASIMHAN; McLEAVEY; BILLINGTON, 1995) são: 1) a soma dos ótimos locais não é igual ao ótimo global; 2) não balanceie a capacidade, balanceie o fluxo; 3) o nível de utilização de um não gargalo é determinado por alguma outra restrição do sistema, não por sua própria capacidade; 4) a utilização e a ativação de um recurso não são sinônimos; 5) uma hora perdida no gargalo é uma hora perdida em todo o sistema; 6) uma hora poupada num recurso não gargalo é uma miragem; 7) Os gargalos governam tanto o throughput como os inventários do sistema; 8) o lote de transferência não precisa ser, e muitas vezes não deveria ser, igual ao lote de processamento; 9) o lote de processamento deveria ser variável, não 
fixo; 10) as prioridades só podem ser estabelecidas analisando as restrições do sistema.

Segundo Goldratt e Cox (2003), é necessário diferenciar os recursos da empresa em dois tipos, gargalos, recursos cuja capacidade é igual ou inferior à demanda alocada a ele, e não gargalos. Neste artigo, o termo gargalo não será utilizado, já que nem sempre o que limita o desempenho do sistema é uma restrição de capacidade. Uma restrição de mercado, por exemplo, pode limitar a utilização dos recursos disponíveis de fabricação. Aqui, o termo CCR (Capacity Constraint Resource) será utilizado para descrever o recurso com maior carga de trabalho em relação à sua capacidade para determinado nível de demanda, ou seja, é o recurso que, para determinado nível de demanda, impõe a cadência de todo o sistema de produção.

Análises da TOC ou do DBR em ambiente de produção não repetitiva, sob encomenda, já aparecem em diversos estudos (GUPTA; KO; MIN, 2002; CHAKRAVORTY, 2001; LEE et al., 2010). Guan et al. (2008) apresentam a utilização da TOC e do DBR em conjunto com o princípio do fluxo contínuo da produção enxuta em ambiente não repetitivo.

\section{Proposta do método}

Esta seção apresenta um método que propõe uma forma de aplicação dos princípios da produção enxuta e da TOC no ambiente da IBCE, com a utilização dos SCOs adequados, para reduzir o lead time de produção e melhorar a pontualidade de entrega, além de simplificar o fluxo de materiais e informações e o processo de PCP. As etapas do método estão presentados na Figura 1.

\subsection{Explicitar o valor (fatores competitivos)}

A primeira etapa consiste em explicitar o valor para os clientes. As empresas da IBCE estão expostas a condições de mercado muito adversas e a redução do lead time e a pontualidade de entrega são valores reconhecidos pelos clientes desse segmento, pois uma entrega mais rápida e pontual permite ao cliente melhor estruturação do fluxo de caixa do projeto, que torna possível: i) postergar o investimento ou; ii) antecipar o início da operação.

\subsection{Definir a PWBS e as famílias de produtos}

Na segunda etapa do método, são definidas a estrutura de projeto orientada a produto (PWBS) e as famílias de produto da empresa. O produto final das empresas na IBCE, que será denominado neste artigo de Equipamento, é geralmente montado fora da planta de produção, devido ao seu tamanho e complexidade, e é composto de muitos níveis de produtos que precisam ser fabricados e sucessivamente agrupados, formando produtos maiores até serem finalmente montados na montagem final do Equipamento. A PWBS, apresentada por Storch e Lim (1999), considera que este Equipamento deve ser subdividido em grandes módulos que possam ser montados e expedidos de forma completa para a montagem final. Esses módulos serão chamados de unidades de montagem que,

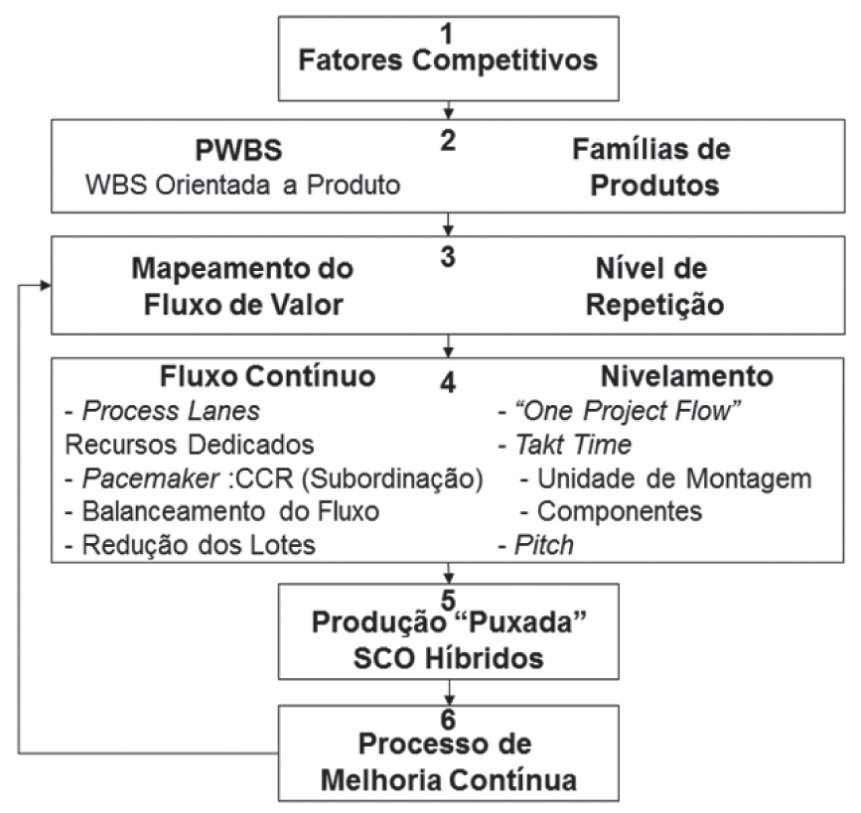

Figura 1. Método de aplicação da produção enxuta e da TOC no ambiente de produção IBCE. 
por sua vez, são compostas por um ou mais níveis de componentes que são os produtos fabricados pela empresa. Portanto, a estrutura de produto será composta de três níveis: i) Equipamento (montado fora da planta de produção); ii) Unidade de Montagem (montado e expedido pela planta de produção); e iii) Componentes (produtos manufaturados pela empresa).

A formação de famílias de produtos na IBCE visa aumentar o nível de repetição nas fases de fabricação dos componentes e deve levar em consideração a estrutura do produto, a similaridade dos processos de fabricação dos componentes e seus tempos de ciclo.

\subsection{Mapear fluxo de valor e analisar o nível de repetição}

O Mapa de Fluxo de Valor (MFV) apresentado por Rother e Shook (2003) é uma ferramenta utilizada para suportar a implementação do princípio do fluxo de valor da produção enxuta proposto por Womack e Jones (1998). Tem a finalidade de compreender o fluxo completo de uma família de produtos, identificar os desperdícios e fontes dos desperdícios, mostrar a relação entre o fluxo de informação e o fluxo de materiais, formar a base para um plano de implementação, além de integrar os princípios e guiar a utilização das ferramentas da produção enxuta, evitando a implementação de algumas técnicas separadamente (ROTHER; SHOOK, 2003).

Na terceira etapa do método, portanto, o ponto de partida para o mapeamento do fluxo de valor deve ser o produto final da família, ou seja, a unidade de montagem, e então decompor o fluxo de fabricação dos componentes dessa unidade, até chegar à matéria-prima.

O nível de repetição de um sistema de produção tem forte influência na escolha do seu sistema de controle de produção (MacCARTHY; FERNANDES, 2000). Ao separar os componentes em famílias e dedicar recursos a elas, aumenta-se o nível de repetição das unidades produtivas que fabricam os componentes. Isso leva à conveniente possibilidade de usar sistemas mais simples para controlar unidades produtivas com maior nível de repetição.

\subsection{Criar fluxo contínuo onde possível e nivelar a produção}

Na quarta etapa do método, o fluxo contínuo e o nivelamento de produção devem ser implementados simultaneamente. Para atingir o fluxo continuo na produção dos componentes, é necessário criar um fluxo unitário de peças (one piece flow) que passe por uma cadeia de recursos dedicados, chamada Process Lane (PL), de acordo com a definição de Storch e Lim (1999), balanceada, com pequenos lotes de produção e programada de acordo com o ritmo do CCR dessa PL. A criação dessas PLs está fortemente ligada aos conceitos de tecnologia de grupo (veja BURBIDGE, 1975) e fábricas focalizadas (veja SKINNER, 1974). As PLs devem conter os recursos necessários para a fabricação de uma família completa de produtos (STORCH; LIM, 1999). Nesse caso, uma PL pode representar, de acordo com seu nível de repetição (Figura 2): i) Linha de Produção: fluxos muito repetitivos; ii) Célula de Produção: fluxos repetitivos ou semirrepetitivos; iii) Minifábrica: para fluxos menos repetitivos.

A formação de PLs com a dedicação de recursos a uma família de produtos pode causar problemas de alocação da carga de trabalho e consequente ocupação dos recursos. Uma solução para tais efeitos é criar PLs "virtuais", ou seja, mesmo mantendo o layout funcional, dedicar temporariamente os recursos de cada jobshop e programá-los como uma linha de produção dedicada a uma família de produtos conforme proposto por Guan et al. (2008).

Além da criação das PLs para atingir o fluxo contínuo e as vantagens de simplificação de programação propostas por este método, é necessário ainda: i) identificar o CCR de cada PL e garantir que não varie de acordo com o mix de produção (evitar CCRs flutuantes); ii) estabelecer lotes de transferência unitários; iii) obter o balanceamento do fluxo de produção, que na IBCE significa o

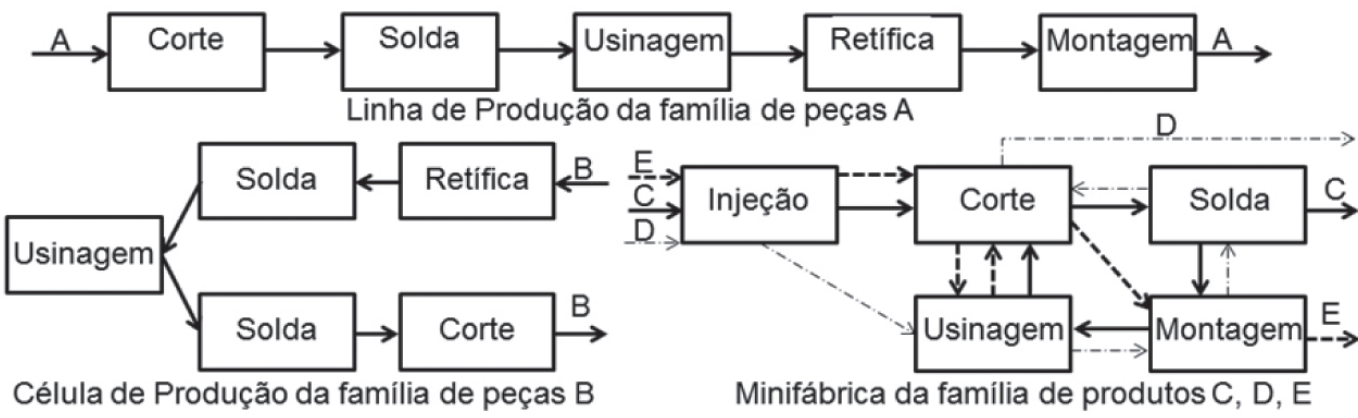

Figura 2. Configurações das PLs (adaptado de SILVA; RENTES, 2002). 
balanceamento das cargas de trabalho dos processos de fabricação, em termos de duração da atividade, ou seja, tempo de ciclo de cada processo; e iv) reduzir os lotes de processamento.

Para realizar o balanceamento da capacidade nesse ambiente, de alta variedade, é necessário: i) formar uma força de trabalho flexível e multifuncional; e ii) manter algum nível planejado de capacidade ociosa (pulmão de capacidade) nos recursos não restritivos para lidar com as flutuações do sistema de produção.

O nivelamento das PLs deve prever o fluxo unitário de projetos (one project flow), ou seja, das unidades de montagem, em cada PL e uma (pequena) antecipação das entregas em relação à data de entrega prometida, o que corresponde a um pulmão de tempo na expedição, utilizado pela TOC para garantir as datas de entrega. A liberação de trabalho para as PLs deve ser feita em um incremento de tempo padronizado, chamado Pitch. Em PLs repetitivas, o Pitch pode ser igual ao Takt Time e, a cada Pitch, um componente deve ser liberado no início da PL. Já em PLs menos repetitivas, em que o volume de trabalho de cada componente varia, o Pitch pode ser definido de acordo com as características de tempos de ciclo de cada PL, e os componentes devem ser medidos em múltiplos de uma unidade padrão (UP), que corresponde ao volume de trabalho de um componente de referência no CCR da PL. Dessa forma, a cada Pitch, deve ser liberada sempre a mesma quantidade de UPs para o CCR dessa PL.

A utilização do Takt Time como elemento de controle do fluxo de materiais na IBCE é mais complexa que em ambientes mais repetitivos, pois pode variar muito em função da quantidade e variedade dos componentes de cada Equipamento. Além disso, um Takt Time de alguns meses é muito longo e difícil de ser utilizado como um meio de dividir as tarefas e definir o ritmo de produção (LIKER; LAMB, 2001). Portanto, o Takt Time deve ser definido separadamente para: i) as unidades de montagem que compõem cada Equipamento; e ii) os componentes fabricados que as compõem.

\subsection{Implementar o princípio da produção puxada por meio de SCOs híbridos}

A finalidade desta quinta etapa do método é implementar a produção puxada, quando o fluxo contínuo não for possível. O SCO típico da produção enxuta é o Kanban, que não é aplicável ao ambiente estudado, pois cada cartão indica a fabricação de um único item específico e circula entre duas estações de trabalho subsequentes (SIPPER; BULFIN, 1997), sendo indicado para sistemas com baixa variedade de itens, demanda relativamente estável e baixos tempos de setup (FERNANDES; GODINHO FILHO, 2010), o que não ocorre na IBCE. Nesse ambiente, se faz necessária a utilização de SCOs híbridos que possam lidar com maior variedade de itens e demanda não estável. Entre os diversos SCOs híbridos existentes, este trabalho indica dois que se adaptam bem a esse ambiente e suportam o método proposto: i) o CONWIP (veja SPEARMAN et al., 1990; HOPP; SPEARMAN, 2004); e ii) o DBR (veja GOLDRATT; FOX, 1989; GOLDRATT, 1991). O SCO deve ser selecionado de acordo com o nível de repetição de cada PL. O CONWIP é recomendável para as PLs mais repetitivas, pois, segundo Fernandes e Godinho Filho (2010), embora possa ser utilizado para famílias de produtos com certo grau de variedade, funciona melhor em sistemas com maior nível de repetição. Já o DBR é recomendável para as PLs menos repetitivas, pois, segundo Goldratt e Fox (1989), a sua lógica não tem limite de aplicação, embora a complexidade de alguns sistemas de produção possa exigir o auxílio de um sistema computadorizado.

\subsection{Implementar um processo de melhoria contínua}

O processo de melhoria contínua segue os seguintes passos: 1) eliminar os desperdícios mais óbvios; 2) delimitar o pulmão de inventário (estoque planejado de peças); 3) determinar o pulmão de capacidade (capacidade ociosa planejada em alguns recursos não restritivos); 4) determinar um pulmão de tempo (antecipação em relação à data planejada) para lidar com a flutuação da demanda; 5) reduzir os desperdícios gradativamente por meio de técnicas como: TPM (Total Productive Maintenance), SMED e trabalho padronizado, para reduzir a variação do tempo de ciclo; 6) reduzir o pulmão de inventário; 7) reavaliar os pulmões de tempo e capacidade; 8) reiniciar o processo (adaptado de HOPP; SPEARMAN, 2004).

\section{Pesquisa-ação: aplicação do método proposto}

\subsection{Apresentação da empresa}

O método proposto foi aplicado e estudado ao longo de sete anos em uma empresa de bens de capital do setor metal-mecânico, fabricante de máquinas e equipamentos para o segmento de papel e celulose, instalada em São Paulo, com 300.000 m² $^{2}$ de área e um total de 4.000 colaboradores nas quatro divisões do grupo, dos quais 1.000 na divisão estudada.

A máquina para fabricação de papel tem a função básica de remover a água contida na polpa de celulose, desde um teor de $0,5 \%$ seco até a consistência final em torno de $90 \%$ de teor seco. Para cumprir tal função e garantir os parâmetros de qualidade do produto final, a máquina é dividida em quatro "seções" (formação, prensagem, secagem e parte final). 
A estratégia de atendimento à demanda da empresa é Engineering to Order (ETO), em que, após a venda, é realizado um trabalho de engenharia de produto e customização dos produtos para atender à necessidade de cada cliente específico. Depois da liberação das listas de materiais pela engenharia de produto, é realizada a transferência dessas listas para um diagrama de rede (cronograma) de cada unidade de montagem e o MRP, suportado por esse diagrama de rede, gera as ordens de compra de itens que serão montados com os componentes fabricados internamente, que são planejados por SCOs diferentes, dependendo da família de produtos a que pertencem. Esses SCOs serão mais bem descritos nas próximas subseções.

A expedição de cada unidade de montagem é planejada e realizada de acordo com a necessidade da montagem de campo em que a máquina de papel será instalada. Enquanto algumas unidades de montagem são montadas na planta do cliente, outras são fabricadas e montadas pela empresa. Ao término da montagem de campo, ocorre o comissionamento, com a interligação final e testes da máquina e início da alimentação de energia, água, óleo, ar, vapor, etc., e, por fim, o início de operação da máquina.

\subsection{Condições de mercado e fatores competitivos: valor}

O mercado global de máquinas de papel e celulose é segmentado em poucas grandes empresas multinacionais europeias que concorrem entre si quando se trata de máquinas de grande porte, alta velocidade e alta tecnologia, cuja demanda está hoje concentrada na Ásia, com atenção especial na China. Nesse mercado, além do preço do projeto, o lead time de entrega dos equipamentos é o fator ganhador de pedido, uma vez que estas empresas oferecem soluções tecnológicas similares. No Brasil, além da presença dessas multinacionais, existe um maior número de empresas nacionais, que competem pela venda de componentes e peças de reserva e pequenas reformas de máquinas existentes. Nesse segmento, o nível de serviço ao cliente, com baixo lead time associado à pontualidade de entrega, são os fatoras ganhadores de pedido. Portanto, nos dois segmentos em que a empresa está inserida, a redução do lead time e a pontualidade de entrega são valores que aumentam o valor para seus clientes.

\subsection{A PWBS da máquina de papel e famílias de produtos}

Conforme apresentado na seção 4.3 , é pré-requisito que a estrutura de projeto seja dividida de forma orientada ao produto, uma PWBS (Figura 3).

A máquina e cada seção estão no nível 1, pois são montados apenas na montagem de campo. A unidade de montagem, no nível 2 é o item de demanda independente do Plano Mestre de Produção (MPS) e é um módulo completo, composto de componentes de nível 3 fabricados internamente, além de todos os subsistemas hidráulicos, elétricos e de automação que são montados e testados na planta de produção, para serem entregues prontos e rapidamente instalados na fase de montagem de campo. A Tabela 1 apresenta a matriz de produtos da empresa e a separação das famílias de produtos de acordo com a similaridade de processos de fabricação dos componentes de cada unidade de montagem.

\subsection{Transformação do chão de fábrica}

O layout original da empresa em 2004, antes da pesquisa-ação, apresentava quatro galpões, cada um com um processo: corte, caldeiraria, usinagem e montagem. Como jobshop clássico, não havia

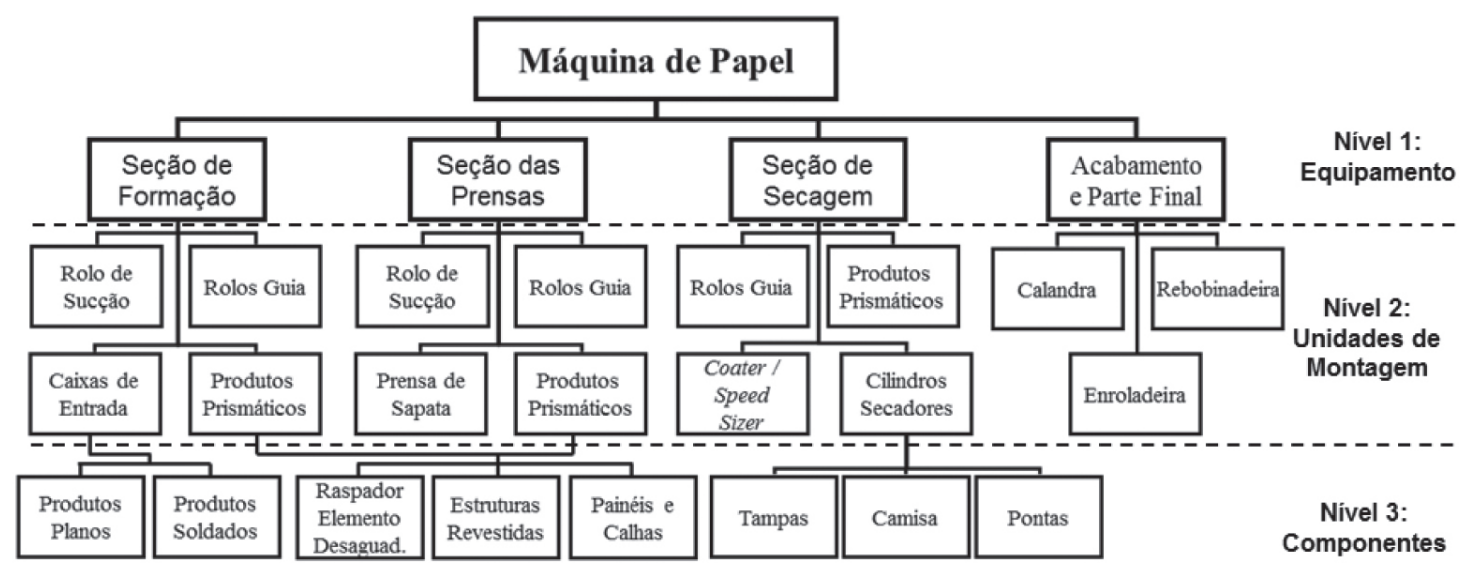

Figura 3. PWBS de uma máquina de papel. 
Tabela 1. Matriz de produtos e família de produtos.

\begin{tabular}{|c|c|c|c|c|c|c|}
\hline Família & Unidade de Montagem & $\begin{array}{c}\text { Corte } \\
\text { Carbono }\end{array}$ & Corte Inox & Calandra & $\begin{array}{c}\text { Montar/ } \\
\text { Soldar }\end{array}$ & $\begin{array}{c}\text { Arco } \\
\text { Submerso }\end{array}$ \\
\hline A & Caixa de Entrada & & $\mathrm{X}$ & & $\mathrm{X}$ & \\
\hline \multirow{2}{*}{ B } & Formação (Produtos Prismáticos) & $\mathrm{X}$ & $\mathrm{X}$ & & $\mathrm{X}$ & \\
\hline & Prensa (Produtos Prismáticos) & $\mathrm{X}$ & $\mathrm{X}$ & & $\mathrm{X}$ & \\
\hline \multirow{3}{*}{$\mathrm{C}$} & Secagem (Produtos Prismáticos) & $\mathrm{X}$ & & & $\mathrm{X}$ & \\
\hline & Enroladeira (Produtos Prismáticos) & $\mathrm{X}$ & & & $\mathrm{X}$ & \\
\hline & Rebobinadeira (Produtos Prismáticos) & $\mathrm{X}$ & & & $\mathrm{X}$ & \\
\hline \multirow{3}{*}{ D } & Rolos Guia & $\mathrm{X}$ & & $\mathrm{X}$ & & $\mathrm{X}$ \\
\hline & Tambores & $\mathrm{X}$ & & $\mathrm{X}$ & & $\mathrm{X}$ \\
\hline & Estangas & $\mathrm{X}$ & & $\mathrm{X}$ & & $\mathrm{X}$ \\
\hline $\mathrm{E}$ & Cilindros Secadores & & & & & \\
\hline Família & Unidade de Montagem & $\begin{array}{l}\text { "Revest./ } \\
\text { Funilaria" }\end{array}$ & Plaina & Fresadora & $\begin{array}{c}\text { Torno } \\
\text { Vertical }\end{array}$ & $\begin{array}{c}\text { Torno } \\
\text { Horizontal }\end{array}$ \\
\hline A & Caixa de Entrada & $\mathrm{X}$ & $\mathrm{X}$ & $\mathrm{X}$ & & \\
\hline \multirow{2}{*}{ B } & Formação (Produtos Prismáticos) & $\mathrm{X}$ & & $\mathrm{X}$ & & \\
\hline & Prensa (Produtos Prismáticos) & $\mathrm{X}$ & & $\mathrm{X}$ & & \\
\hline \multirow{3}{*}{$\mathrm{C}$} & Secagem (Produtos Prismáticos) & & & $\mathrm{X}$ & & \\
\hline & Enroladeira (Produtos Prismáticos) & & & $\mathrm{X}$ & & \\
\hline & Rebobinadeira (Produtos Prismáticos) & & & $\mathrm{X}$ & & \\
\hline \multirow{3}{*}{$\mathrm{D}$} & Rolos Guia & & & & & $\mathrm{X}$ \\
\hline & Tambores & & & & & $\mathrm{X}$ \\
\hline & Estangas & & & & & $\mathrm{X}$ \\
\hline $\mathrm{E}$ & Cilindros Secadores & & & & $\mathrm{X}$ & $\mathrm{X}$ \\
\hline Família & Unidade de Montagem & $\begin{array}{l}\text { Teste de } \\
\text { Pressão }\end{array}$ & $\begin{array}{c}\text { Eletro- } \\
\text { polimento }\end{array}$ & Decapagem & Pintura & Montagem \\
\hline A & Caixa de Entrada & & $\mathrm{X}$ & $\mathrm{X}$ & & $\mathrm{X}$ \\
\hline \multirow{2}{*}{ B } & Formação (Produtos Prismáticos) & & & $\mathrm{X}$ & & $\mathrm{X}$ \\
\hline & Prensa (Produtos Prismáticos) & & & $\mathrm{X}$ & & $\mathrm{X}$ \\
\hline \multirow{3}{*}{$\mathrm{C}$} & Secagem (Produtos Prismáticos) & & & & $\mathrm{X}$ & $\mathrm{X}$ \\
\hline & Enroladeira (Produtos Prismáticos) & & & & $\mathrm{X}$ & $\mathrm{X}$ \\
\hline & Rebobinadeira (Produtos Prismáticos) & & & & $\mathrm{X}$ & $\mathrm{X}$ \\
\hline \multirow{3}{*}{$\mathrm{D}$} & Rolos Guia & & & & $\mathrm{X}$ & $\mathrm{X}$ \\
\hline & Tambores & & & & $\mathrm{X}$ & $\mathrm{X}$ \\
\hline & Estangas & & & & $\mathrm{X}$ & $\mathrm{X}$ \\
\hline E & Cilindros Secadores & $\mathrm{X}$ & & & $\mathrm{X}$ & $\mathrm{X}$ \\
\hline
\end{tabular}

recursos dedicados a um tipo de produto, o que tornava o fluxo de valor muito pouco repetitivo, uma vez que todos os tipos de produtos eram produzidos simultaneamente nos mesmos jobshops.

A transformação do layout foi um processo gradativo, iniciado com uma família de produtos e a criação de PLs "virtuais", ou seja, dedicando os recursos no jobshop original e, numa segunda etapa, criando as PLs com layout em minifábricas ou linhas de produção. Até o fim da pesquisa-ação, no ano de 2011, quatro famílias de produtos já eram produzidas em PLs que passaram por mudança de layout e uma (família B) ainda era produzida no jobshop remanescente, entretanto, com todos os recursos desses jobshops dedicados a essa família de produtos. Ao término da pesquisa-ação, as PLs são:

- A) PL de Caixa de Entrada: minifábrica;

- B) PL de Produtos Prismáticos (seção das prensas/ formação): jobshop dedicado (está prevista até 2014 a mudança do jobshop remanescente em minifábricas para esta família de produtos);

- C) PL de Produtos Prismáticos em aço carbono (seção de secagem/parte final): minifábricas;

- D) PL de Rolos Guia: linha de produção;

- E) PL de Cilindros Secadores: linha de produção.

Nas seções 5.5 e 5.6, serão apresentados os projetos das famílias E e B, com o resumo da implementação das etapas 3, 4 e 5 do método para cada família. 


\subsection{Cilindros secadores - família E}

A quantidade de cilindros secadores em uma máquina varia bastante dependendo do tipo e gramatura do papel e velocidade da máquina, podendo variar de 30 a mais de 100 cilindros em uma única máquina. Trata-se de um produto modular, que passa apenas por uma etapa de customização após a venda, ou seja, um projeto padrão é customizado para atender às características de cada máquina. $\mathrm{Na}$ empresa, existem apenas dois centros de produção para esse produto, a planta chinesa que atende ao mercado asiático, e a brasileira, que atende às demais regiões, o que garante o alto nível de demanda desse produto.

Os componentes fabricados do cilindro secador são: camisa, tampas direita e esquerda, pontas direita e esquerda. Outros componentes são comprados e montados durante a montagem do cilindro (termo anel, união rotativa, mancais e sifão estacionário).

A produção do cilindro pode ser dividida em três grandes etapas: a fundição dos componentes (camisa, tampas e pontas); a usinagem de cada um desses; e a montagem dos componentes e usinagem final do cilindro. A fundição pertence a outra unidade do grupo e será tratada como um fornecedor. Os demais processos estão apresentados no MFV da Figura 4, que apresenta a situação inicial, antes do projeto da pesquisa-ação (2004). A fabricação do cilindro secador é repetitiva: cada produto passa pelos mesmos processos, variando apenas o tempo de ciclo de três processos principais de usinagem e retífica $(2,4$ e 9$)$, que variam de acordo com a dimensão dos cilindros que, por sua vez, depende da largura da máquina de papel. No mapeamento, foi utilizado um cilindro de dimensões médias, na faixa de larguras e diâmetros que a empresa mais vende.

O caminho crítico da fabricação dos componentes é a usinagem da camisa, realizada em duas etapas de usinagem, externa e interna (2 e 4), além de três etapas manuais de preparação e inspeção (1, 3 e 5). A usinagem das tampas direita e esquerda é realiza em um torno vertical (14) e em uma furadeira (15). Já as pontas, são usinadas em um torno horizontal CNC (17) em duas fases. Depois da inspeção (16 e 18) de cada um desses componentes, são realizadas a montagem e a prensagem das pontas de eixo em suas respectivas tampas e destas no cilindro, numa etapa única (6). Em seguida, é realizado o teste pressão (7), para certificação de vaso de pressão, e o cilindro segue para as etapas finais de usinagem (8), retífica (9), balanceamento (10), acabamento (11), pintura (12) e montagem final dos demais componentes (13).

$\mathrm{Na}$ situação inicial, as máquinas eram compartilhadas com outras famílias de produtos e todas as máquinas trabalhavam em dois turnos. O PCP central passava as ordens de produção para o setor de usinagem que fazia a programação de cada máquina individualmente, em função da sua disponibilidade e da data de montagem dos cilindros. Muitos projetos eram fabricados ao mesmo tempo, causando longos tempos de setup e variação nos tempos de ciclo entre uma peça e a seguinte. $\mathrm{O}$ processo de maior tempo de ciclo é a usinagem externa da camisa (2). Esse processo, o CCR, foi definido como o pacemaker (processo cadenciador).

O primeiro passo do nivelamento foi a fabricação de um projeto por vez, one project flow, o que permitiu reduzir o lead time de fabricação de cada projeto individualmente. Por ser um produto mais padronizado, composto do mesmo número de componentes, o Takt Time efetivo de um dia garante um incremento de trabalho padronizado para todos os processos.

Com o novo layout em linha de produção, a dedicação das máquinas e a redução do estoque em processo entre cada uma das máquinas, o lote de transferência unitário passou a ser utilizado na

\section{Antes da Pesquisa-Ação (Out/2004)}

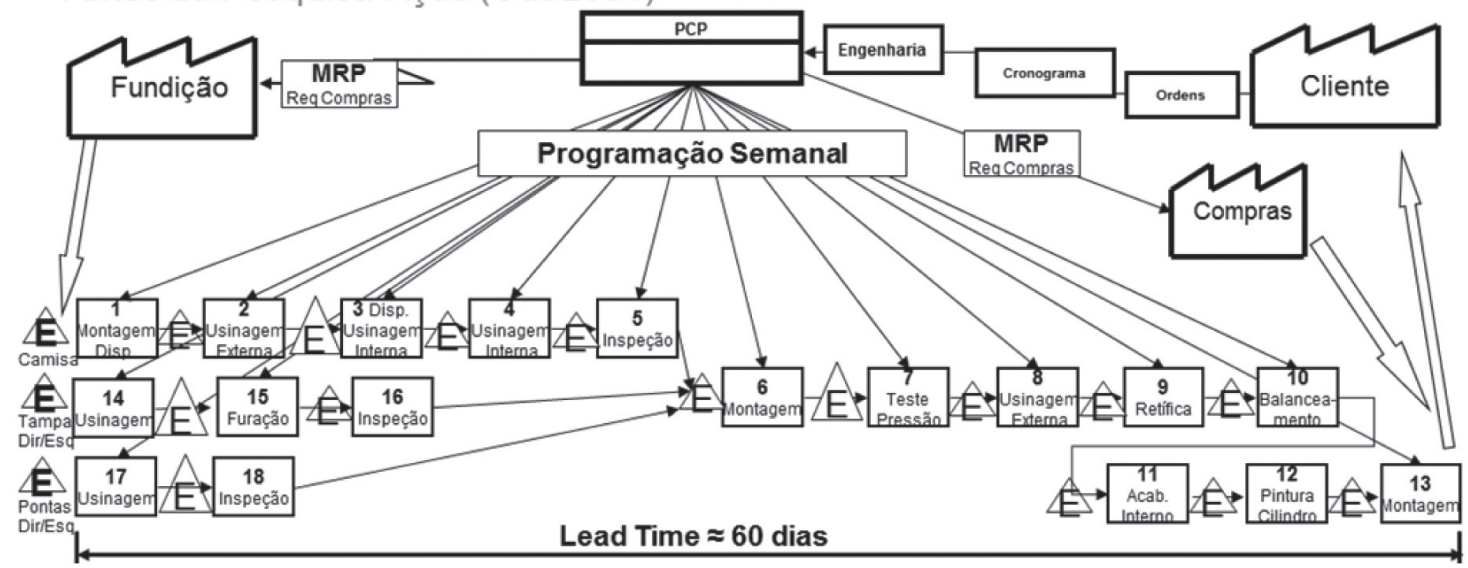

Figura 4. MFV do cilindro secador - antes da pesquisa-ação. 
fabricação da camisa, montagem e usinagem final do cilindro, possibilitando a criação do fluxo contínuo de peças desde a usinagem da camisa até a montagem final e acabamento. Já, com a produção de um único projeto por vez, o lote de processamento se torna igual ao número de cilindros de cada projeto.

O passo seguinte, o balanceamento, foi realizado com a alocação adequada de recursos, mão de obra e máquinas, de forma que todos os centros de trabalho pudessem produzir no mesmo ritmo, o Takt Time de um dia, mantendo o fluxo contínuo, unitário de peças. Durante essa fase, foi realizado um estudo detalhado das atividades de cada colaborador em cada máquina, com a identificação dos tempos manuais e automáticos de cada operação, bem como o treinamento dos colaboradores para que pudessem operar os diversos processos dessa PL. Dessa forma, cada posto de trabalho passou a ativar apenas a quantidade de horas por turno, necessária para atender o Takt Time. Da mesma forma, alguns processos com tempos de ciclo curtos puderam ser agrupados em um mesmo posto de trabalho (os processos manuais 12 e 13 foram grupados no processo 11), de forma que o tempo de ciclo total desse novo processo fosse próximo ao Takt Time. De forma oposta, a montagem do cilindro (6), um processo longo de montagem executado em três turnos, foi dividida em duas etapas: a montagem das tampas com as pontas de eixo (20), formando dois subconjuntos tampa-ponta, e a montagem desses subconjuntos com a camisa (6), formando o cilindro. Com tal divisão e o trabalho padronizado desta atividade (padronização das atividades e das ferramentas, além do treinamento dos montadores), o tempo ciclo da montagem do cilindro (6) foi reduzido para um turno. A Figura 5 apresenta o MFV com a situação após o projeto de pesquisa-ação.

O SCO híbrido proposto para essa PL foi o CONWIP que, conforme apresentado na seção 4.6, é recomendado para PLs mais repetitivas. Uma backlog list com a sequência e as ordens de produção dos cilindros secadores é enviada ao primeiro processo de cada componente $(1,14$ e 17). A autorização para iniciar a fabricação de cada componente é dada pela disponibilidade de cartões, cuja quantidade é constante na linha.

Cada ponta de eixo é acompanhada de um cartão que é liberado quando a ponta é utilizada na montagem das tampas (19). Da mesma forma, cada tampa segue com um cartão que é liberado quando é utilizada na montagem do cilindro (6). A camisa segue em fluxo contínuo e o cartão que a acompanha continua com o cilindro até o final do processo de montagem e acabamento (11), e só é liberado quando o cilindro é entregue para a expedição. Pulmões de inventário são planejados tanto após o término de fabricação das pontas (18) quanto após a montagem das tampas (19), antes da montagem do cilindro (6), para garantir que a camisa, que passou pelo CCR da PL, não fique parada aguardando componentes dessa outra ramificação. Toda a programação da linha é feita para o CCR, que é planejado de acordo com a sequência de expedição e do Takt Time efetivo de um dia.

\subsection{Produtos prismáticos - família B}

A família B é a que apresenta maior variedade de componentes. Dentro da mesma família, estão os produtos prismáticos das seções de formação e prensa de todos os tipos de máquinas de papel. Portanto,

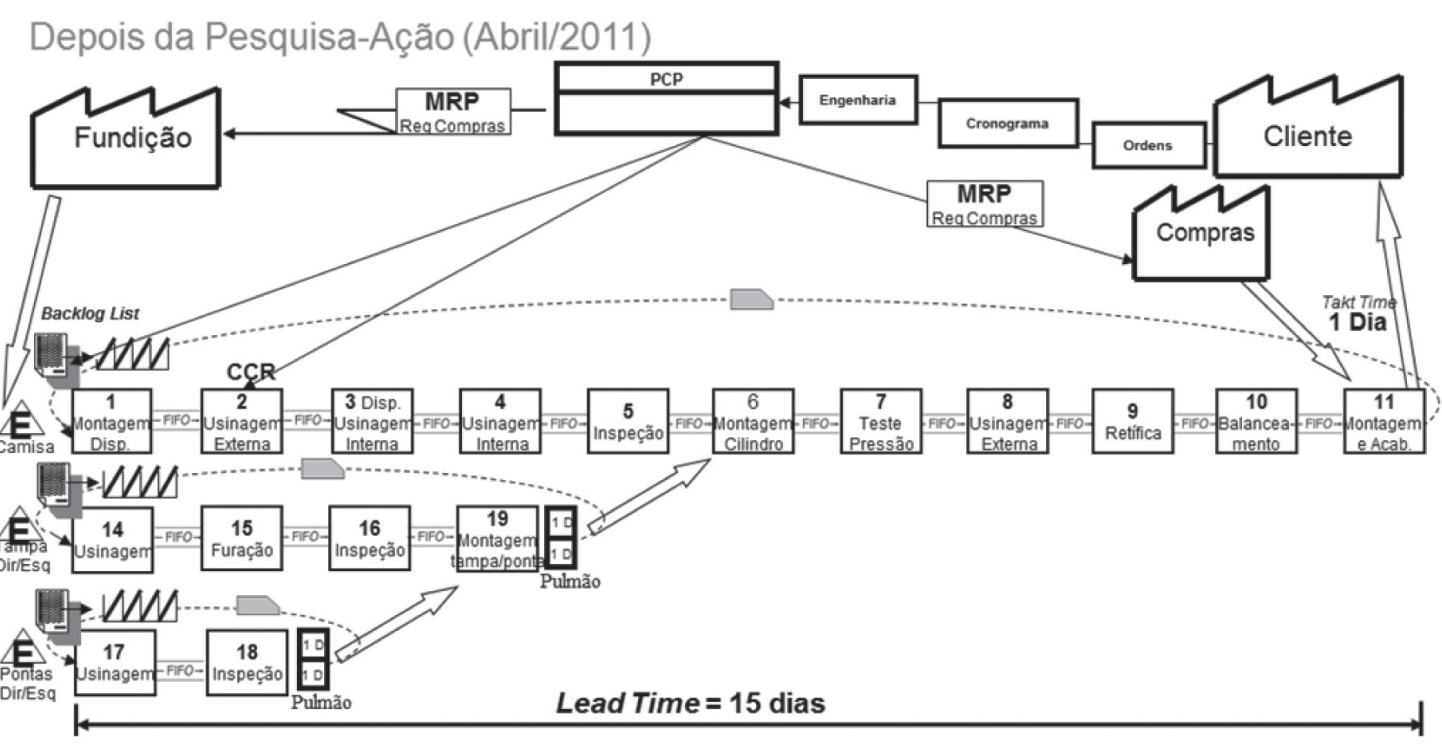

Figura 5. MFV do cilindro secador - depois da pesquisa-ação. 
as unidades de montagem são distintas umas das outras, cada uma sendo formada por um número e variedade diferente de componentes. Mesmo com a criação das primeiras PLs e a separação das demais famílias de produtos, essa família de produtos ainda apresentava um fluxo não repetitivo em função da variedade de componentes.

A Figura 6 apresenta o MFV de uma unidade de montagem (nesse caso, uma seção de formação de uma máquina de papel embalagem de 6 metros de largura de tela) produzida em 2004, antes do início desta pesquisa-ação. Nessa situação inicial, todos os componentes eram fabricados pelos mesmos recursos compartilhados com as famílias de produtos A e C nos jobshops originais: corte; caldeiraria (montagem/ solda e revestimento/funilaria); usinagem; tratamento superficial; e montagem.

O PCP central passava as ordens de produção para os setores de corte, caldeiraria e usinagem, que faziam a programação individual de cada recurso em função da disponibilidade e da data de montagem de cada unidade de montagem. Muitas unidades de montagem das famílias A, B e C eram montadas simultaneamente no jobshop de montagem, causando longos lead times de montagem (em torno de 50 dias no caso mapeado). Consequentemente, muitos componentes de unidades de montagem diferentes eram fabricados ao mesmo tempo em cada jobshop, com longos lead times de fabricação, causados pelo grande volume de estoque em processo (WIP) em cada jobshop e constantes reprogramações em razão da falta de priorização entre cada unidade de montagem. $\mathrm{O}$ grande volume de WIP em cada jobshop era consequência dos grandes lotes de processamento e transferência no corte e na caldeiraria, em que cada componente era fabricado por apenas um colaborador que trabalhava em mais de um componente simultaneamente. Além disso, toda a equipe estava alocada em um único turno.

Novamente, o primeiro passo do nivelamento foi a definição da fabricação e montagem de um projeto por vez, one project flow. As montagens de cada unidade de montagem passaram a ser programadas para ocorrer sem simultaneidade com outras montagens da mesma família, o mais próximo possível da data de entrega, mas levando em consideração uma antecipação, ou pulmão de tempo, antes da expedição (Figura 7). Isso permitiu a alocação maior de recursos em cada montagem, reduzindo assim o lead time desse processo (em torno de $20 \%$ de redução). Dessa forma, foi possível priorizar a fabricação dos componentes de uma unidade de montagem por vez, eliminando também a simultaneidade nos demais processos, o que simplificou e estabilizou a programação de cada recurso.

Para aumentar o nível de repetição do fluxo de valor, essa família $\mathrm{B}$ de produtos foi dividida em três subfamílias (B1, B2 e B3), cada uma composta por componentes com roteiros similares, ou seja,

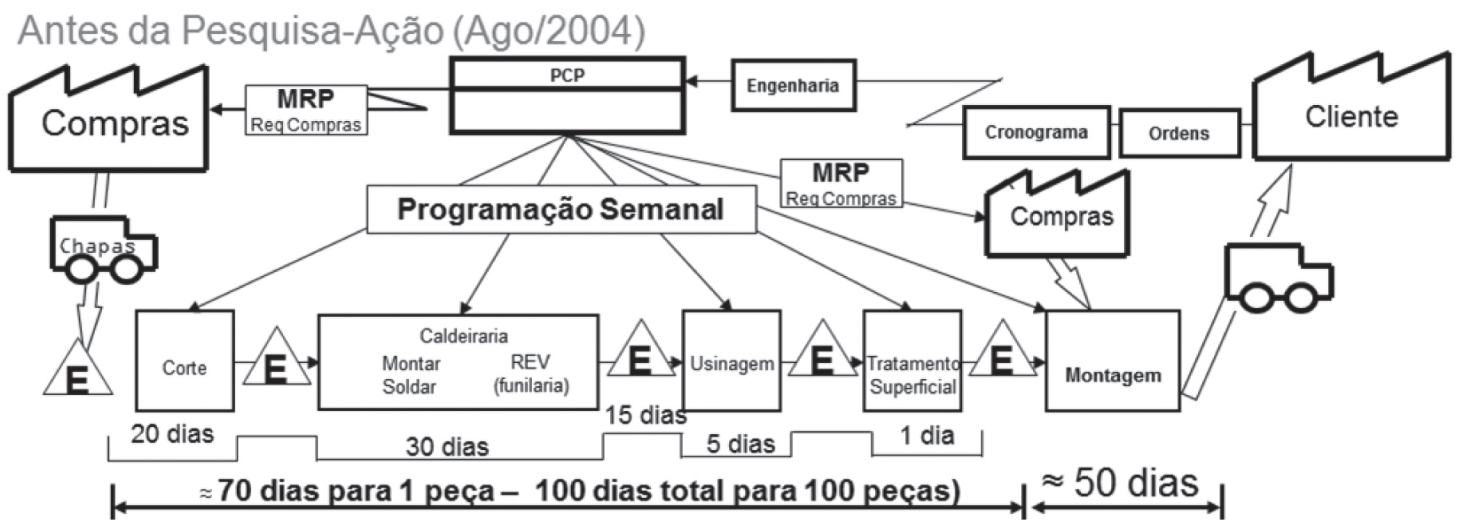

Figura 6. MFV de produtos prismáticos (seção de formação) - antes da pesquisa-ação.

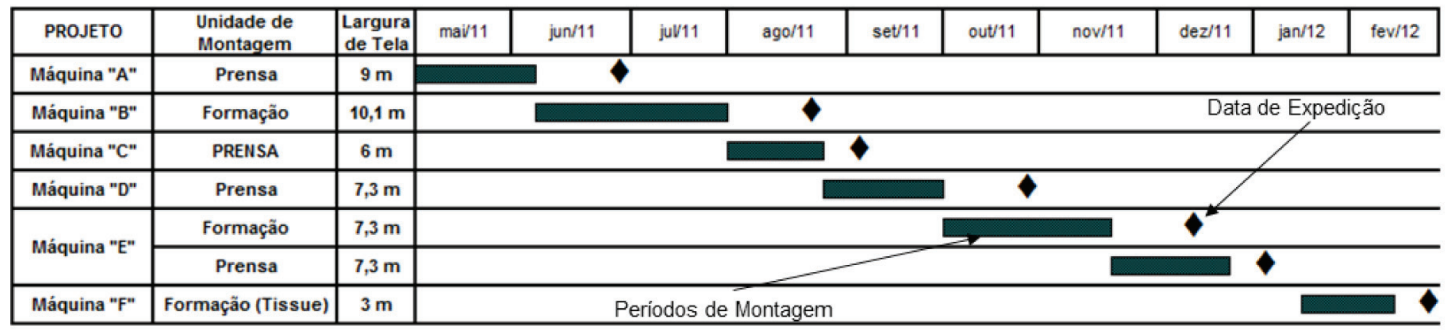

Figura 7. Nivelamento da montagem: família de produtos B. 
que apresentam a mesma sequência de fabricação (Tabela 2). Os componentes foram divididos em três grupos que diferem basicamente no seu processo de caldeiraria: B1) componentes soldados de aço carbono, revestidos de chapa fina de aço inoxidável (estruturas); B2) componentes soldados de aço inoxidável (raspadores e elementos desaguadores); e B3) componentes de chapas finas de aço inoxidável (calhas). Para tanto, após a divisão e formação das PLs das demais famílias de produtos (A, C, D e E), o jobshop remanescente foi dividido em três PLs secundárias para a fabricação dos componentes dessas três subfamílias (B1, B2 e B3). O resultado foi o aumento do nível de repetição, com a transformação de um fluxo não repetitivo em três PLs semirrepetitivas.

As PLs secundárias são uma divisão da PL dedicada para a fabricação da família B e os componentes fabricados nas três PLs secundárias são utilizados na montagem da mesma unidade de montagem. Essas PLs secundárias são flexíveis, uma vez que a quantidade de recursos dedicados em cada uma pode variar de acordo com o mix de componentes que será fabricado para a montagem de determinada unidade de montagem.

A mudança de mix de componentes influencia tanto o nivelamento como o balanceamento do CCR. Cada PL secundária tem um CCR, o processo de caldeiraria (montar/soldar e revestimento/funilaria), que apresenta os maiores tempos de ciclo. $\mathrm{O}$ nivelamento da produção de cada PL é baseado em um Pitch desse processo e seu balanceamento é realizado de acordo com o mix de componentes ao longo de um determinado horizonte de tempo, de acordo com o tipo de unidade de montagem que será fabricada.

Para nivelar a produção das PLs secundárias, é necessário identificar a demanda do CCR de cada uma delas, e definir o período necessário para os CCRs das três PLs fabricarem todos os componentes de determinada unidade de montagem. Identificar a demanda para o CCR das PLs secundárias significa verificar a quantidade e tamanho dos componentes que compõem cada unidade de montagem e dividi-los nas subfamílias B1, B2 e B3. Por se tratar de PLs semirrepetitivas, com maior diversidade de produtos, cada componente é mensurado de acordo com o volume de trabalho necessário no CCR para produzi-lo. Esse volume de trabalho é medido em unidades padrão (UP), que é o volume de trabalho necessário no CCR para se produzir o menor componente dessa família de produtos (nesse caso, uma UP representa aproximadamente 30 horas-homem de trabalho de caldeiraria).

O passo seguinte é a programação detalhada da montagem de cada unidade de montagem, que dará tanto a sequência de fabricação de cada PL quanto as datas programadas para a chegada dos demais componentes comprados que são utilizados na montagem. Com essa sequência, é realizada a programação detalhada do CCR, a caldeiraria, de cada PL secundária, que determinará o ritmo de produção de toda a PL, que varia de acordo com o mix de componentes de cada unidade de montagem.

Para exemplificar o nivelamento de produção e o balanceamento dessa PL, foi desenhado um novo MFV após a implementação do projeto de pesquisa-ação (Figura 8). Para permitir a comparação, foi utilizada uma unidade de montagem fabricada em 2006, similar à utilizada no MFV inicial (Figura 6) com dimensões, quantidade e complexidade de componentes aproximadas. Essa unidade de montagem (uma seção de formação de uma máquina de papel embalagem, de 7,3 metros de largura de tela) possui 110 componentes fabricados, divididos nas três subfamílias.

A Tabela 3 apresenta o nivelamento e o balanceamento das três PLs secundárias para a fabricação dos componentes da unidade de montagem em um período de 50 dias no CCR. O Pitch para esta PL foi definido em cinco dias. Portanto, a cada período de cinco dias, um volume de trabalho constante para o CCR deve ser liberado no início de cada PL. Como são PLs semirrepetitivas, em que

Tabela 2. Divisão das subfamílias de produtos - família B.

\begin{tabular}{|c|c|c|c|c|c|c|}
\hline Subfamília & Componentes & Corte Carbono & $\begin{array}{l}\text { Corte } \\
\text { Inox }\end{array}$ & $\begin{array}{c}\text { Caldeiraria } \\
(\text { Montar/Soldar })\end{array}$ & $\begin{array}{l}\text { "Caldeiraria (Rev } \\
\text { Inox Funilaria)" }\end{array}$ & CNC \\
\hline B1 & Estruturas Revestidas & $X$ & $X$ & $\mathrm{X}$ & $X$ & $X$ \\
\hline \multirow{2}{*}{$\mathrm{B} 2$} & Elementos Desaguadores & & $\mathrm{X}$ & $\mathrm{X}$ & & $\mathrm{X}$ \\
\hline & Raspadores & & $\mathrm{X}$ & $\mathrm{X}$ & & $\mathrm{X}$ \\
\hline B3 & Calhas & & $\mathrm{X}$ & & $\mathrm{X}$ & \\
\hline Subfamília & Componentes & $\begin{array}{c}\text { "Fresadora } \\
\text { Convencional" }\end{array}$ & Furação & Decapagem & Montagem & \\
\hline B1 & Estruturas Revestidas & $\mathrm{X}$ & $\mathrm{X}$ & $\mathrm{X}$ & $\mathrm{X}$ & \\
\hline \multirow{2}{*}{ B2 } & Elementos Desaguadores & $\mathrm{X}$ & $\mathrm{X}$ & $\mathrm{X}$ & $\mathrm{X}$ & \\
\hline & Raspadores & $\mathrm{X}$ & $\mathrm{X}$ & $\mathrm{X}$ & $\mathrm{X}$ & \\
\hline B3 & Calhas & & & $\mathrm{X}$ & $\mathrm{X}$ & \\
\hline
\end{tabular}




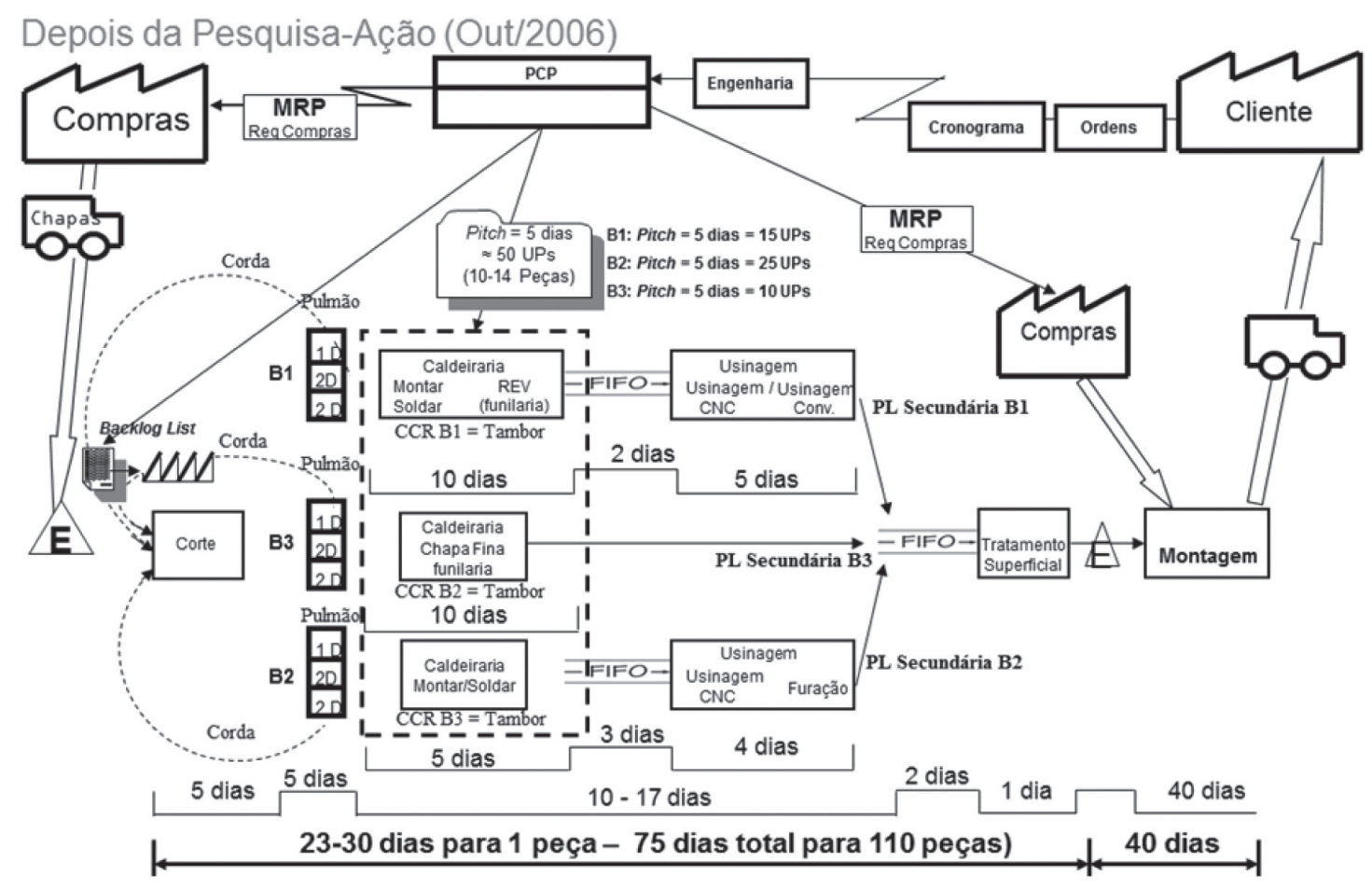

Figura 8. MFV de produtos prismáticos (seção de formação) - depois da pesquisa-ação.

cada componente representa um volume de trabalho diferente no CCR, a liberação de trabalho é feita em quantidades constantes de UPs a cada período. Cada componente foi mensurado em UPs, e o total de UPs divido em dez períodos de cinco dias. Dessa forma, a cada cinco dias é liberada a mesma quantidade de UPs para cada PL secundária. Por exemplo, a subfamília B1 (estruturas revestidas) tem um total de 30 componentes, mensurados em um total de 150 UPs, ou seja, são liberadas 15 UPs a cada período de cinco dias. Entretanto, em função da variedade dos componentes, este mesmo volume de 15 UPs pode representar de três a cinco componentes que devem ser fabricados nesse período no CCR. Para completar o balanceamento, foram alocados três colaboradores na usinagem dessa PL B1.

Na Tabela 3, são apresentadas as subfamílias de componentes que são fabricadas em cada PL secundária: a divisão dos 110 componentes nas PLs; a quantidade de UPs que estes componentes representam em cada CCR; a quantidade de UPs que devem ser produzidas em um Pitch em cada CCR; a variação no número de componentes que este $P i t c h$ representa; o número de colaboradores de caldeiraria alocados em cada CCR; e o número de colaboradores de usinagem alocados em cada PL.

Para reduzir o lead time de fabricação dos componentes e buscar o fluxo contínuo, foi necessário reduzir o estoque em processo nas PLs secundárias.
Para tanto, foi necessária a redução do tamanho dos lotes de processamento e de transferência nos processos de corte e caldeiraria. No processo de corte, foram tomadas ações em duas áreas diferentes da empresa: i) uma mudança no processo de engenharia de produto para reduzir a quantidade de espessuras de chapas em um mesmo componente; e ii) mudança no software de detalhamento de chapa e controle de retalhos no estoque, que permite, ao mesmo tempo, planejar o melhor aproveitamento de chapas, com um número maior de componentes, e cortar apenas as chapas necessárias para formar um ou dois componentes por vez. Dessa forma, a mesma chapa entra e sai da máquina de corte mais de uma vez, ao contrário do que ocorria antes, aumentando o número de setups, porém reduzindo o tamanho dos lotes de processamento e transferência.

Para lidar com o aumento do número de setups, algumas ações foram realizadas para reduzir o tempo de setup (SMED), como: transformação das atividades de preparação das ferramentas e das chapas de atividades internas, realizadas com a máquina parada, em atividades externas, que passaram a ser realizadas antes da parada da máquina; a utilização de elementos de fixação rápida e a padronização desses elementos; e documentação e padronização das atividades de setup bem como o treinamento dos operadores. Tais ações permitiram reduzir o tempo de setup em torno de $50 \%$. 
Tabela 3. Balanceamento e nivelamento da PL - família B.

\begin{tabular}{clccc}
\hline $\begin{array}{c}\text { PL Secundária } \\
\text { Subfamília }\end{array}$ & \multicolumn{1}{c}{ Componentes } & Qtde & UPs & $\begin{array}{c}\text { "UPs / Pitch } \\
\text { Pitch = 5 dias" }\end{array}$ \\
\hline B1 & Estruturas Revestidas & 30 & 150 & 15 \\
\hline B2 & Desaguadores/Raspadores & 65 & 250 & 25 \\
\hline B3 & Calhas & 15 & 90 & 49 \\
\hline Total & Componentes & Componentes / & $\begin{array}{c}\text { Colaboradores } \\
\text { Caldeiraria (CCR) }\end{array}$ & $\begin{array}{c}\text { Colaboradores } \\
\text { Usinagem }\end{array}$ \\
\hline $\begin{array}{c}\text { PL Secundária } \\
\text { Subfamília }\end{array}$ & Pitch & 12 & 3 \\
\hline B1 & Estruturas Revestidas & $3-5$ & 20 & 5 \\
\hline B2 & Desaguadores/Raspadores & $6-7$ & 8 & não tem usinagem \\
\hline B3 & Calhas & $1-2$ & 40 & 8 \\
\hline Total & & $10-14$ & & \\
\hline
\end{tabular}

Já na caldeiraria, as mudanças para redução dos tamanhos dos lotes foram tanto na formação dos colaboradores, com uma parcela precisando ser treinada para executar todas as atividades de caldeiraria (montar/soldar e revestimento/funilaria), quanto na divisão igual dos turnos e do trabalho em si. O intuito foi o de utilizar o maior número de colaboradores em um único componente em todo o processo de caldeiraria, reduzindo o tempo de ciclo de cada componente e, ao mesmo tempo, o tamanho do lote de processamento e transferência.

Por se tratar de três PLs semirrepetitivas, o SCO híbrido escolhido utiliza os princípios do DBR que, conforme apresentado na seção 4.6, é recomendado para PLs menos repetitivas. O CCR, a caldeiraria, funciona como o tambor (drum) e trabalha com recursos dedicados para cada PL secundária. A programação é feita em função de sua capacidade e da sequência definida pela montagem. Daí para frente, com a redução dos lotes de transferência da caldeiraria apresentada anteriormente, o fluxo é contínuo, unitário, para os recursos de usinagem e tratamento superficial. Para trás, a liberação de trabalho é realizada de acordo com o Pitch do CCR, ou seja, a cada cinco dias, um volume de trabalho de cinco dias do CCR deve ser liberado. Entretanto, o processo de corte atende às três PLs secundárias, ou seja, é compartilhado para as três subfamílias B1, B2 e B3. Foi então definido um pulmão (buffer) também de cinco dias entre o corte e cada um dos CCRs, de forma que, conforme o consumo de cada pulmão pelo CCR, uma informação, a corda (rope), é passada para o corte, e o mix de produção do corte pode ser ajustado. Apesar de esse pulmão de cinco dias ser significativo no lead time de fabricação, foi fundamental para dar estabilidade para o CCR e lidar com a flutuação do processo de corte, decorrente da variação do número de chapas a serem cortadas em um mesmo período, que varia com o mix de componentes fabricados.
Nesse caso, o lead time de fabricação de um componente, desde o início até chegar à montagem, varia de 23 a 30 dias, dependendo da PL secundária. Para a fabricação de todos os 110 produtos, são mais 45 dias após o término dos primeiros componentes, pois o ritmo é, em média, 11 componentes a cada cinco dias nas três PLs. Portanto, o lead time de fabricação de todos os componentes dessa unidade de montagem é de aproximadamente 75 dias. Já, a montagem tem duração de 40 dias e ocorre simultaneamente com o final da fabricação. Para cada novo projeto, de acordo com a unidade de montagem que será fabricada, um novo mapeamento é realizado com as definições da demanda, ritmo, balanceamento, nivelamento e lead time, apresentados anteriormente.

\subsection{Melhoria contínua}

As etapas apresentadas nas seções anteriores seguiram o processo de melhoria contínua, incremental, apresentado na seção 4.7. Os primeiros MFVs desenhados (Figuras 4, 6) tornaram visíveis os desperdícios mais óbvios (tempos de transporte e espera dos materiais, excesso de produção em alguns recursos e desbalanceamento de outros, etc.). A transformação do chão de fábrica do jobshop original em PLs e o balanceamento dessas PLs reduziram tais desperdícios (dedicação e aproximação de recursos, redução dos lotes, etc.), de acordo com a primeira etapa do processo de melhoria contínua.

Já, a implementação dos SCOs híbridos e o nivelamento de produção focaram as três etapas seguintes do processo: 2) delimitação dos pulmões de inventário (de tampas e pontas na seção 5.5 e de componentes cortados antes da caldeiraria na seção 5.6); 3) determinação do pulmão de capacidade, com a manutenção de um determinado nível de capacidade ociosa em alguns recursos não restritivos para lidar com a variação do tempo de ciclo dos CCRs de cada PL (nos processos de usinagem interna e retífica no primeiro caso e no corte e 
usinagem no segundo); e 4) determinação do pulmão de tempo, com a antecipação das datas de montagem em relação à data planejada de entrega, apresentado nos dois casos. À medida que os primeiros resultados apareceram, alguns desperdícios se tornaram mais evidentes e foram atacados, de acordo com a etapa 5 do processo de melhoria contínua, como: variação e longos tempos de setup no processo de corte apresentado na seção 5.6, reduzidos por meio do trabalho de SMED e padronização do trabalho nesse processo; falta de treinamento de alguns operadores que faziam variar demasiadamente o tempo de ciclo nos processos mais manuais como a montagem do cilindro, atacados por meio do trabalho padronizado da montagem apresentado na seção 5.5; quebra frequente de máquinas da usinagem, reduzida com a implementação do TPM para algumas máquinas mais críticas, como a retífica de cilindros e fresadora CNC.

A estabilização decorrente das melhorias implementadas na quinta etapa permitiu a revisão dos pulmões, de acordo com as etapas 6 e 7 desse processo. Até o fim da pesquisa-ação, fim de 2011, os pulmões de tempo e capacidade não foram reduzidos, mas eram continuamente monitorados. Já, os pulmões de inventário foram reduzidos gradativamente, tanto na PL da família E, quanto na da família B (50\% do pulmão de inventário inicial), nesse mesmo período. Toda vez que ocorre alguma melhoria no fluxo de valor em função das etapas anteriores, um novo mapeamento é realizado de forma a identificar se surgiram novos CCRs, novos desperdícios ou mesmo novas oportunidades, como o desligamento de uma máquina, a alocação de um recurso para a fabricação de um novo produto, etc., dando início a um novo ciclo de melhoria, a etapa 8 desse processo de melhoria contínua.

\section{Conclusões}

Tendo em vista os objetivos e questões da pesquisa, as conclusões estão a seguir enunciadas. Nem todas as ferramentas e técnicas da produção enxuta (por exemplo, o Kanban) são igualmente aplicáveis à IBCE, dadas suas características de baixo volume e alta variedade de produtos, que implicam a variação dos tempos de ciclo e altos tempos de setup, layout funcional, longos lead times de cada projeto, além da própria produção sob encomenda, que não permite a manutenção de estoques de produtos finais e componentes, o que dificulta o nivelamento de produção. Para superar tais desafios, o método propôs a implementação da TOC como suporte aos princípios da produção enxuta nesse ambiente.

O método propôs a divisão do projeto em uma PWBS, com a definição de um módulo chamado de unidade de montagem que é o produto final da planta de produção; a separação dos componentes que compõem tal unidade em famílias de produtos fabricados em fluxos de valor dedicados a cada uma dessas famílias, as PLs, de forma a aumentar o nível de repetição na fabricação desses componentes; desenvolver e manter um fluxo contínuo e uniforme de fabricação; definir o CCR como o pacemaker dessas PLs, por meio da programação desse recurso, de forma a atender ao Takt Time da PL, e da subordinação dos demais recursos a essa programação; nivelar a produção programando a fabricação de um único projeto por vez em cada PL, one project flow; e controlar o chão de fábrica por meio de SCOs híbridos, que devem ser escolhidos de acordo com o grau de variedade da família de produtos e, portanto, do nível de repetição de cada PL.

Assim, este artigo cumpre o objetivo da pesquisa-ação de resolver um problema prático e contribui com a ciência na medida em que propõe e aplica, por meio da pesquisa-ação, um método para a implementação dos princípios da produção enxuta e da TOC no ambiente de produção da IBCE para reduzir o tempo de resposta e melhorar a pontualidade de entrega, e responde às duas questões de pesquisa. Em resposta à primeira, este trabalho apresentou que, apesar da necessidade da escolha correta das práticas e ferramentas da produção enxuta e de certas adaptações, os princípios da produção enxuta em conjunto com a TOC podem ser aplicados a determinados sistemas de produção de bens de capital sob encomenda. Já, em resposta à segunda questão de pesquisa, este trabalho confirma pela pesquisa-ação que os SCOs, CONWIP e DBR podem ser utilizados para sustentar os princípios da produção enxuta e da TOC no ambiente estudado e sugere que cada PL seja controlada por um SCO híbrido coerente com seu nível de repetição: CONWIP para PLs mais repetitivas e o DBR para PLs menos repetitivas. Das cinco famílias de produto da empresa, foram apresentadas apenas duas, com diferentes níveis de repetição, para mostrar a aplicabilidade do método a diferentes situações e níveis de repetição e exemplificar a lógica de utilização de cada SCO.

Para finalizar, é necessário ressaltar três pontos referentes à pesquisa-ação:

- i) O método proposto é resultado da simbiose entre teoria e prática e emergiu da pesquisa e experiência realizadas. Foi desenvolvido com base na pesquisa das abordagens apresentadas e dos fatores inerentes ao ambiente da IBCE, nas diversas iniciativas realizadas pela empresa para otimizar seu sistema de produção e na própria experiência dos pesquisadores no ambiente da IBCE, tendo o primeiro autor trabalhado dez anos na empresa alvo da pesquisa-ação e o segundo com mais de 35 anos de experiência e pesquisas no setor. Ao longo da implementação, decorrente do sucesso ou fracasso de certas hipóteses e inciativas implantadas, o método 
passou por diversas modificações até chegar ao resultado final sumarizado na Figura 1. No primeiro momento, por exemplo, se tentou reorganizar o sistema de produção utilizando apenas os princípios e ferramentas da produção enxuta que, embora tenham apresentado alguns resultados iniciais positivos na redução de lead time, trouxeram alguns problemas de programação e falta de estabilidade do fluxo de materiais, decorrentes da alta variedade de produtos, o que frustrou tal iniciativa. A pesquisa das diversas abordagens adotadas por empresas da IBCE levou à adoção da TOC e dos SCOs propostos, em conjunto com a produção enxuta, como forma de superar tais dificuldades.

- ii) Entre os diversos SCOs híbridos existentes, o CONWIP e o DBR foram propostos neste artigo por estarem ligados às duas abordagens propostas pelo método. O CONWIP tem sido utilizado em implementações da produção enxuta (BOKHORST; SLOMP; GERMS, 2009) e, segundo Spearman et al. (1990), trata-se de uma generalização do Kanban para alcançar os benefícios da produção enxuta em situações de maior variedade e mix de produtos. Já o DBR nasceu dos cinco passos da TOC e é uma generalização das regras que deram origem ao sistema OPT, inicialmente desenvolvido por Goldratt.

- iii) Embora o método tenha sido proposto para ser utilizado por diversos tipos de empresas da IBCE, ele foi testado apenas na empresa alvo da pesquisa-ação que o originou, sendo possível afirmar que ele é aplicável a situações similares às apresentadas na seção 5 , em que um sistema de produção inicialmente não repetitivo, como um jobshop, pode ser adequadamente subdividido em fluxos de valor mais repetitivos, permitindo o surgimento de PLs repetitivas e semirrepetitivas. É importante ressaltar que algumas empresas da IBCE, fornecedoras de uma gama maior de equipamentos de bens de capital, que atendem a diversos segmentos diferentes, trabalham com uma variedade muito grande de produtos, o que dificulta a dedicação de recursos ou mesmo a criação de famílias de produtos. Além disso, outra limitação ao método proposto ocorre em sistemas de produção em que cada produto é um novo protótipo, "criado a partir do zero", que passa por processos totalmente independentes e não repetitivos como empresas que trabalham apenas com pesquisa e desenvolvimento para indústria militar ou espacial. Os autores consideram, no entanto, que esta não é a realidade da maioria das empresas da IBCE, que geralmente fabricam certa gama de produtos, previamente desenvolvidos, que são customizados para cada cliente específico, mantendo, portanto, suas características e processos de manufatura padronizados.

Quanto a futuros trabalhos de pesquisa, sugerem-se: i) estudo de múltiplos casos no ambiente de bens de capital para comprovação da eficácia do método apresentado em outras empresas desse segmento; ii) estudo da aplicação de outros SCOs (POLCA (Paired-cell Overlapping Loops of Cards with Authorization), o LOOR (Load Oriented Order Release) e o PBC (Period Batch Control) em conjunto com o método apresentado para situações mais complexas; e iii) aplicação dos processos de raciocínio da TOC como forma de auxiliar a tomada de decisões ao longo do processo de implementação do método.

\section{Referências}

ALVAREZ, R. R.; ANTUNES JUNIOR, J. A. V. Takt Time: contexto e contextualização dentro do Sistema Toyota de Produção. Gestão \& Produção, v. 8, n. 1, p. 01-18, abr. 2001.

BAMBER, L.; DALE, G. Lean production: a study of application in a traditional manufacturing environment. Production Planning \& Control, v. 11, n. 3, p. 291-298, 2000. http://dx.doi. org/10.1080/095372800232252

BANCO NACIONAL DE DESENVOLVIMENTO - BNDES. A Indústria de implementos rodoviários e sua importância para o aumento da eficiência do transporte de cargas no Brasil. BNDES Setorial, n. 24, p. 241-260, set. 2006.

BOKHORST, J. A. C.; SLOMP, J.; GERMS, R. A Lean production control system for high variety/low volume environment: A case study implementation. Production Planning \& Control, v. 20, n. 7, p. 586-596, 2009. http://dx.doi.org/10.1080/09537280903086164

BURBIDGE, J. L. The introduction of group technology. London: Heinemann, 1975.

CHAKRAVORTY, S. S. An Evaluation of the DBR control mechanism in a job shop environment. The International Journal of Management Science, v. 29, p 29 335-342, 2001.

COUGHLAN, P.; COGHLAN, D. Action research for operation management. International Journal of Operations and Production Management, v. 22, n. 2, p. 220-240, 2002. http://dx.doi. org/10.1108/01443570210417515

CRUTE, V. et al. Implementing lean in aerospace - challenging the assumptions and understanding the challenges. Technovation, v. 23, n. 12, p. 917-928, 2003. http://dx.doi.org/10.1016/ S0166-4972(03)00081-6

DUDLEY, A. N. The application of lean manufacturing principles in a high mix low volume environment. 2005. 
Thesis (M.B.A)-Massachusetts Institute of Technology, Massachusetts, 2005. Disponível em <http://hdl.handle. net/1721.1/34828>. Acesso em: 29 mar. 2010.

ESWARAMOORTHI, M.; KATHIRESAN, G. R.; MOHANRAM, P. V. A Survey on lean practices in Indian machine tool industries. International Journal of Advanced Manufacturing Technology, v. 52, n. 9-12, p. 1091-1101, 2010. http://dx.doi.org/10.1007/ s00170-010-2788-y

FERNANDES, F. C. F.; GODINHO FILHO, M. Planejamento e Controle da Produção: dos fundamentos ao essencial. São Paulo: Editora Atlas S/A., 2010.

GAMBI, L. N. Recomendações para implementação de conceitos e técnicas de produção enxuta em empresas, fabricantes de produtos sob encomenda do aglomerado industrial de Sertãozinho. 2011. Dissertação (Mestrado)-Escola de Engenharia de São Carlos, Universidade de São Paulo, São Carlos, 2011.

GOLDRATT, E. M. A Síndrome do palheiro: garimpando informação num oceano de dados. São Paulo: IMAM, 1991.

GOLDRATT, E. M.; COX, J. A Meta: um processo de melhoria contínua. 2. ed. São Paulo: Nobel, 2003.

GOLDRATT, E. M.; FOX, R. E. A corrida pela vantagem competitiva. São Paulo: IMAN, 1989.

GUAN, Z. et al. Operation and control of flow manufacturing based on constraints management for high-mix/ low volume production. Frontiers of Mechanical Engineering in China, v. 3, n. 4, p. 454-461, Dec 2008. http://dx.doi.org/10.1007/s11465-008-0083-5

GUPTA, M.; KO, H-J.; MIN, H. TOC-based performance measures and five focusing steps in a job-shop manufacturing environment. International Journal of Production Research, v. 40, n. 4, p. 907-930, 2002. http://dx.doi.org/10.1080/00207540110097185

HENDRY, L. C. Applying world class manufacturing to make to order companies: problems and solutions. International Journal of Operations and Production Management, v.18, n. 11, p. 1086, 1998. http://dx.doi. org/10.1108/01443579810231679

HINES, P.; TAYLOR, D. Going lean: a guide to implementation. Cardiff: Lean Enterprise Research Center, 2000.

HOPP, W. J.; SPEARMAN, M.L. To pull or not to pull: what is the question? Manufacturing and Service Operations Management, v. 6, n. 2, p. 133-148, 2004. http://dx.doi.org/10.1287/msom.1030.0028

IRANI, S. A. Value stream mapping in custom manufacturing and assembly facilities. Columbus: Department of Industrial, Welding and Systems Engineering, The Ohio State University, 2001.

JINA, J.; BHATTACHARYA, A. K.; WALTON, A. D. Applying lean principles for high product variety and low volumes: Some Issues and Propositions. Logistics Information Management, v. 10, n. 1, p. 5-13, 1997. http://dx.doi.org/10.1108/09576059710159655

LEE, J. H. et al. Research on enhancements of TOC simplified Drum-Buffer-Rope system using novel generic procedures. Expert Systems with Applications, v. 37, p. 3747-3754, 2010. http://dx.doi.org/10.1016/j. eswa.2009.11.049

LIKER, J. O Modelo Toyota: 14 princípios de gestão do maior fabricante do mundo. Porto Alegre: Bookman, 2005.

LIKER, J.; LAMB, T. Lean shipbuilding. lean Manufacturing principles guide. Develop and Implement a "World Class" manufacturing. A guide to lean shipbuilding. Michigan: Maritech ASE Project, 2001.

LITTLE, D. et al. Integrated planning and scheduling in the engineering-to-order sector. International Journal of Integrated Manufacturing, v. 13, n. 6, p. 545-554, 2000. http://dx.doi.org/10.1080/09511920050195977

MacCARTHY, B. L.; FERNANDES, F. C. F. A multidimensional classification of production systems for the design and selection of production planning and control systems. Production Planning \& Control, v. 11, n. 5, p. 481-496, 2000. http://dx.doi. org/10.1080/09537280050051988

MEGLIORINI, E. Análise crítica dos conceitos de mensuração utilizados por empresas brasileiras produtoras de bens de capital sob encomenda. 2003. Tese (Doutorado)-Universidade de São Paulo, São Paulo, 2003.

MONDEN, Y. Sistema Toyota de Produção. São Paulo: IMAM, 1984.

NARASIMHAN, S.; McLEAVEY, D. W.; BILLINGTON, P. Production panning and inventory control. 2nd ed. Englewood Cliffs: Prentice Hall, 1995.

OHNO, T. O Sistema Toyota de Produção: além da produção em larga escala. Porto Alegre: Bookman, 1997.

ROTHER, M.; SHOOK, J. Aprendendo a enxergar: mapeando o fluxo de valor para agregar valor e eliminar o desperdício. 3. ed. São Paulo: Lean Institute Brasil, 2003.

SHINGO, S. O Sistema Toyota de Produção: do ponto de vista de engenharia de produção. Porto Alegre: Bookman, 1996. PMid:8905671.

SIEVÄNEN, M. The effects of customization on capital goods manufacturing business. 2004. Thesis (Ph.D.)Tampere University of Technology, Tampere, 2004.

SILVA, A. L.; RENTES, A. F. Tornando o layout enxuto com base no conceito de mini-fábricas num Ambiente de multi-produtos: um estudo de caso. In: ENCONTRO NACIONAL DE ENGENHARIA DE PRODUÇÃO, 22., 2002, Curitiba. Anais... Curitiba, 2002.

SIPPER, D.; BULFIN, R. Production: planning, control, and integration. New York: McGraw-Hill, 1997.

SKINNER, W. The focused factory. Harvard Business Review, p. 113-121, May/June 1974.

SPEARMAN, M. L.; WOODRUFF, D. L.; HOPP. W. J. CONWIP: A pull alternative to kanban. International Journal of Production Research, v. 28, n. 5, p. 879-894, 1990. http://dx.doi. org/10.1080/00207549008942761

STEFANELLI, P. Modelo de programação da produção nivelada para produção enxuta em ambiente ETO com alta variedade de produtos e alta variação de tempos de ciclo. 2010. Dissertação (Mestrado)-Escola de Engenharia de São Carlos, Universidade de São Paulo, São Carlos, 2010.

STORCH, R. L.; LIM, S. Improving flow to achieve lean manufacturing in shipbuilding. Production Planning 
\& Control, v. 10, n. 2, p. 127-137, 1999. http://dx.doi. org/10.1080/095372899233280

THIOLLENT, M. Metodologia da Pesquisa-ação. 9. ed. São Paulo: Cortez, 2000.

THOMPSON, C. G. Uma avaliação do potencial de aplicação da mentalidade enxuta (Lean Thinking) na construção naval: estudo de casos múltiplos. 2009. Dissertação (Mestrado)-Escola Politécnica, Universidade de São Paulo, São Paulo, 2009.

TURRIONI, J. B.; MELLO, C. H. P. Pesquisa-ação na engenharia de produção. In: MIGUEL, P. A. C. (Coord.). Metodologia de pesquisa em engenharia de produção e gestão de operações. Rio de Janeiro: Elsevier Editora, 2010.

VERMULM, R. O Setor de bens de capital. In: SCHWARTZMAN, S. Ciência e tecnologia no Brasil: política industrial, mercado de trabalho e instituições de apoio. Rio de Janeiro: Fundação Getúlio Vargas, 1995. v. 2. WATSON, K. J.; BLACKSTONE, J. H.; GARDINER, S. The evolution of a management philosophy: the theory of constraints. Journal of Operations Management, v. 25, n. 3, p. 387-402, 2007. http://dx.doi.org/10.1016/j. jom.2006.04.004

WHITE, R. E.; PRYBUTOK, V. The relationship between JIT practices and type of production system. Omega: The International Journal of Management Science, v. 29, n. 2, p. 113-124, 2001.

WOMACK, J. P.; JONES, D. T.; ROOS, D. A Máquina que mudou o mundo. 17. ed. Rio de Janeiro: Campus, 1992.

WOMACK, J. P.; JONES, D. T. A Mentalidade enxuta nas empresas: elimine o desperdício e crie riqueza. 8. ed. Rio de Janeiro: Campus, 1998. 
